\title{
Singles and Faces: High Recogni- tion for Female Faces in Single Males
}

\author{
Mohamad El Haj', 2,3, Ahmed A. Moustafa ${ }^{4}$, and Jean-Louis Nandrino \\ ' Nantes Université, Univ Angers, Laboratoire de Psychologie des Pays de la Loire (LPPL - EA 4638), F-44000 Nantes, France \\ ${ }^{2}$ Unité de Gériatrie, Centre Hospitalier de Tourcoing, Tourcoing, France \\ ${ }^{3}$ Institut Universitaire de France, Paris, France \\ ${ }^{4}$ School of Social Sciences and Psychology \& Marcs Institute for Brain and Behaviour, Western Sydney University, Sydney, Australia \\ ${ }^{5}$ Univ. Lille, CNRS, CHU Lille, UMR 9193 - SCALab - Sciences Cognitives et Sciences Affectives, F-59000 Lille, France
}

\section{KEYWORDS}

face recognition

gender differences

evolutionary theory

relationship status

ABSTRACT

A substantial body of research has assessed the effect of gender on face recognition; however, little is known about the effect of relationship status on face recognition. In this study, we assessed for the first time how relationship status impacts face recognition by asking 62 male and female participants to decide whether they had previously encountered faces of males and females. Participants were also asked to fill a socio-demographic variables questionnaire which included, among other information, question about their relationship status (i.e., single vs. in a relationship). A significant effect of relationship status on face recognition was observed only in males; namely, single males demonstrated higher face recognition than males in relationships, whereas similar face recognition was observed in single and in-relationship females. More specifically, single males demonstrated higher recognition for female than for male faces, whereas no differences were observed in single females, males in relationships, or in females in relationship. Single males seem to be motivated by mating opportunity and, thus, unlike single females or males and females in relationships, devote high attentional resources to processing faces of the opposite gender.

\section{INTRODUCTION}

Face processing is a crucial social cognitive ability. Unsurprisingly, substantial literature has been devoted to this topic. Like many other cognitive abilities, face processing has been found to be influenced by gender, as reported in a numerous studies (Caplan, Crawford, Hyde, \& Richardson, 1997; Halpern, 2000; Kimura, 1999; Sommer, Hildebrandt, Kunina-Habenicht, Schacht, \& Wilhelm, 2013; Voyer, Voyer, \& Bryden, 1995). There is, for instance, evidence that males are better than females at performing visuo-spatial working memory tasks (for a review, see Cornoldi \& Vecchi, 2004). In contrast, studies suggest that females are better than males at performing a variety of verbal episodic memory tasks (for a review, see Ullman, Miranda, \& Travers, 2008). The superiority of females in verbal processing has been also observed for autobiographical memory, that is, memory for personal experiences (Conway, 2005; Rubin, Schrauf, \& Greenberg, 2003). For instance, studies have reported that females often describe autobiographical events with more details (Grysman, 2017; Nahari \& Pazuelo, 2015) including basic factual details (Grysman, Merrill, \& Fivush, 2016).

Interestingly, some studies suggest that females outperform males in tasks involving face recognition, independent of face age and ethnicity (Herlitz \& Lovén, 2013; Herlitz, Reuterskiold, Loven, Thilers, \&

Corresponding author: Mohamad El Haj, Faculté de Psychologie, LPPL - Laboratoire de Psychologie des Pays de la Loire, Université de Nantes, Chemin de la Censive du Tertre, BP 81227, 44312 Nantes Cedex 3, France. E-mail: mohamad.elhaj@univ-nantes.fr 
Rehnman, 2013; McBain, Norton, \& Chen, 2009; Rehnman \& Herlitz, 2006, 2007). The advantage of females in face recognition can be attributed to better perception of emotional expressions. Females are better at recognizing and interpreting emotional facial expressions, a difference already apparent in infancy (McClure, 2000). There is also evidence that, on an attentional level, females process faces faster and more efficiently than males (Bowles et al., 2009; Godard \& Fiori, 2010, 2012; Megreya, Bindemann, \& Havard, 2011; Sommer et al., 2013). In a similar vein, infant girls spend more time looking at faces than boys do (Connellan, Baron-Cohen, Wheelwright, Batki, \& Ahluwalia, 2000). The advantage of females in face processing can be significantly observed specifically for female faces: Research suggests that females perform at a higher level for female faces than for male faces (Cross, Cross, \& Daly, 1971; Lewin \& Herlitz, 2002; Wright \& Sladden, 2003). The advantage of females in face processing in general can also be attributed to a general greater interest and knowledge of social aspects of the world (Kaplan, 1978; Rehnman \& Herlitz, 2007). Finally, the advantage females have in processing of female faces perhaps reflects the fact that that females' social interest is specifically directed towards other females (Loven, Herlitz, \& Rehnman, 2011).

Besides gender differences, face recognition may be impacted by relationship status (i.e., single vs. in a relationship). Single individuals may be more motivated by mating interest, and consequently, be more oriented toward the opposite gender than individuals in relationships. Accordingly, single individuals may be specifically interested in processing and retaining physical attributes (e.g., faces) related to the opposite gender. This proposal is in agreement with the derogation effect, that is, the observation that single individuals tend to rate the attractiveness of opposite-gender individuals as higher than individuals in relationships (Karremans, Dotsch, \& Corneille, 2011; Lydon, Meana, Sepinwall, Richards, \& Mayman, 1999; Ritter, Karremans, \& van Schie, 2010; Simpson, Gangestad, \& Lerma, 1990). Support for the effect of relationship status on face processing can also be found in studies demonstrating that single individuals pay more attention to opposite-gender individuals than do individuals in relationships (Maner, Gailliot, \& Miller, 2009; Maner, Gailliot, Rouby, \& Miller, 2007; Maner, Miller, Moss, Leo, \& Plant, 2012; Maner, Rouby, \& Gonzaga, 2008). More specifically, Maner et al. (2009) found that whereas single participants increased implicit attention to physically attractive opposite gender targets, participants in relationships were inattentive to such stimuli.

The potential effect of relationship status on face processing can be also understood in light of studies on mating motivations. Confer, Perilloux, and Buss (2010) asked participants to consider dating, in short- or long-term, an opposite gender individual whose face and body were hidden, respectively, by a "face box" and a "body box". Participants were instructed that only one box could be removed to make their mating decision. Results showed that men prioritized facial cues in long-term mating contexts, but shift their priorities toward bodily cues in short-term mating contexts, whereas females prioritized facial cues over bodily cues regardless of the mating context. Similar findings were observed by Lu and Chang (2012) who found that when considering short- rather than long-term mating contexts, males' attention was significantly influenced by the waist/hip area rather than the face on photographs of attractive women. In contrast, females did not demonstrate such an influence in response to photographs of attractive men. Lu and Chang (2012) argue that perceptual attention in males has evolved to selectively process reproductive information about the opposite gender as a function of short- versus long-term mating goals. The effect of the mating context on face recognition was also reported by Wagstaff, Sulikowski, and Burke (2015), who observed that when prompted for a short- rather than a long-term relationship, male participants showed an increase in their preference for looking at female bodies rather than faces, whereas female participants did not show this difference and generally preferred to look at male faces. Together, research suggests that females' perception of males' faces is not context-dependent, whereas males seem to show a bias toward low processing of females' faces when considering a short-term mating context. Importantly, none of these studies have considered the participants' relationship status.

To summarize, while there is a body of evidence suggesting gender differences in memory for faces, little is known about the effect of relationship status on this type of memory. Our study addressed this issue by assessing face recognition in single versus. in-relationship male and female participants. Regardless of their relationship status, based on literature suggesting female superiority in face recognition (Herlitz \& Lovén, 2013; Herlitz et al., 2013; McBain et al., 2009; Rehnman \& Herlitz, 2006, 2007), we expected to find superior face recognition in female participants. We also expected a higher face recognition accuracy for the opposite gender faces in single participants, especially single males, than in participants in relationships.

\section{METHOD}

\section{Participants}

Sixty-two native French speaker students at the University of Lille participated in the study ( 32 females and 30 males, $M_{\text {age }}=23.06, S D=$ 4.95). At the beginning of the experiment, participants completed a form about their age, gender, relationship status (i.e., single vs. in a relationship), occupation, and history of psychiatric or neurological disorders. We excluded six participants with psychiatric/neurological disorders from the original sample $(N=68)$. We also excluded participants who performed two $S D$ s below the mean score on the episodic memory task by Grober and Buschke (1987). On this task, participants had to remember 16 words, each describing an item belonging to a different semantic category; after a $20 \mathrm{~s}$ distraction phase, they had to recall as many words as they could; the maximum score is 16 points. The mean score of participants was $12.34(S D=3.13)$.

\section{Procedures}

Participants were informed in advance that they had to retain faces for a later recognition task (for a similar use of intentional encoding in face recognition, see Golby, Gabrieli, Chiao, \& Eberhardt, 2001; Rehnman \& 


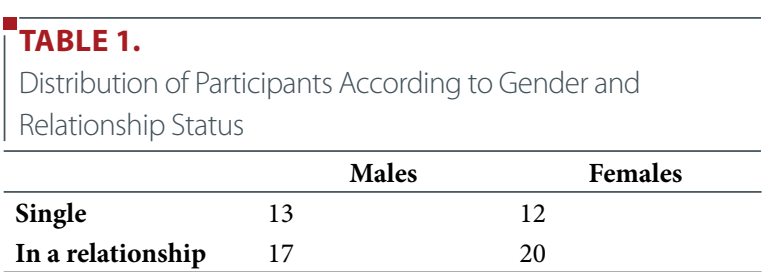

Herlitz, 2007). However, in order not to interfere with the relationship status variable, no mention of it was made in the instructions. In line with studies on face recognition (Rehnman \& Herlitz, 2006), our task included 48 colored faces, taken from the FACES database (Ebner, Riediger, \& Lindenberger, 2010), including 24 male and 24 female faces aged from 18 to 25 years old. This age interval was chosen to control for any potential own age bias, that is, the fact that young participants perform worse in recognizing older than young adult faces (Rhodes \& Anastasi, 2012). In the FACES database, faces had similar size, lighting conditions, and orientation. All faces depicted neutral expressions, so as to control for any potential effect of emotion on recognition (El Haj, Antoine, \& Nandrino, 2016; El Haj, Fasotti, \& Allain, 2015; El Haj, Raffard, Antoine, \& Gely-Nargeot, 2015).

The task was designed with the Psychopy (Peirce, 2007) software package. We used a Dell laptop computer with a $15 \mathrm{in.} \mathrm{LCD} \mathrm{display.} \mathrm{The} \mathrm{task}$ included an encoding, an interpolated, and a recognition phase. On the encoding phase, each of 24 pictures (12 males +12 females) was presented for $1 \mathrm{~s}$ (interstimulus interval: $1 \mathrm{~s}$ ). The encoding phase was followed by the interpolated phase (implemented to prevent reliance on immediate memory) in which participants had to read aloud strings of three-digit numbers for one minute. Afterward, participants proceeded to the recognition phase, in which 48 pictures were presented (the previous 24 pictures +24 distractors). Pictures were randomly presented, with no time constraint. For each picture, participants responded whether it was presented in the previous phase by pressing a green key or whether it was new by pressing a red key. The dependent variable was recognition scores (hits minus false alarms), as recommended for analyzing recognition memory (Snodgrass \& Corwin, 1988).

\section{RESULTS}

We first compared the number of single participants and participants in relationships in the two gender groups. We then compared recognition scores for female and male faces according to the gender and relationship status of our participants. We also compared episodic memory scores according to the participants' gender and relationship status, so as to control whether any potential gender/relationship status differences would be observed in face recognition only or in episodic memory in general. For all tests, the level of significance was set at $p \leq .05$

\section{Similar Distribution of Relationship Status}

The distribution of the participants according to their gender and relationship status is depicted in Table 1. Chi square test showed no significant differences between single participants and participants in relationships in the two gender groups, $\chi^{2}(1, N=62)=.22, p>.10$.

\section{High Recognition for Female Faces in Single Males}

We conducted a repeated-measures analysis of variance (ANOVA) using recognition scores (depicted in Figure 1), the participants' gender (male vs. female) and their relationship status (single vs. in a relationship) as the between-participants factors and the gender of faces (male vs. female) as the repeated-measure factor. Analyses showed a significant effect of participant gender, $F(1,58)=28.92, p<.001, \eta^{2}=.33$. Female participants showed higher face recognition than male participants, with respective means of $.80(S D=.17)$ and $.58(S D=.22)$. The effect of relationship status was also significant, $F(1,58)=21.42, p<.001$, $\eta^{2}=.27$. Further, single participants showed higher face recognition than participants in relationships, with respective means of $.78(S D=$ $.17)$ and $.59(S D=.23)$. The interaction between participant gender and their relationship status was significant, $F(1,58)=4.79, p<.05, \eta^{2}=.08$. Higher face recognition was observed in single males than in males in relationships, $t(28)=4.71, p<.001$, with respective means of .72 (SD $=.15)$ and $.43(S D=.17)$. However, no significant differences were observed between single females and females in relationships, $t(30)=1.68$, $p>.1$. Higher face recognition was also observed in single females than in single males, $t(23)=2.17, p<.05$, with respective means of .85 (SD $=.15)$ and $.72(S D=.15)$. Higher face recognition was also observed in females than males in relationships, $t(35)=5.76, p<.001$, with respective means of $.75(S D=.16)$ and $.43(S D=.17)$. The effect of face gender was significant, $F(1,58)=3.92, p<.05, \eta^{2}=.11$. Higher recognition was observed for female than for male faces, with respective means of .74 $(S D=.28)$ and $.64(S D=.26)$; this effect was, however, observed only in female participants, $t(31)=2.11, p<.05$, with respective means of .84 $(S D=.20)$ and $.73(S D=.23)$. The interaction between relationship status and face gender was significant, $F(1,58)=3.95, p<.05, \eta^{2}=.12$. Single participants demonstrated higher recognition for female faces than for male faces, $t(24)=2.85, p<.01$, with respective means of $.87(S D=.17)$ and $.69(S D=.26)$, whereas participants in relationships demonstrated similar recognition for both female and male faces, $t(33)=.65, p>.10$. Finally, the interaction between participant gender, their relationship status, and face gender was significant, $F(1,58)=3.89, p<.05, \eta^{2}=.09$. Single males demonstrated higher recognition for female than for male faces, $t(12)=2.49, p<.05$, with respective means of $.83(S D=.20)$ and .60 $(S D=.25)$. However, similar recognition was observed in single females and in females and males in relationships.

\section{Similar Episodic Memory in Single Participants and Participants in Relationships}

Episodic memory scores, as obtained on the task by Grober and Buschke (1987), are depicted in Table 2 . We conducted a $2 \times 2$ (Participant Gender [females, males] $\times$ Relationship Status [ single, in a relationship]) ANOVA on these scores. Analyses showed a significant effect of gender, $F(1,58)=4.11, p<.05, \eta^{2}=.07$, females showed higher episodic memory than males, with respective means of $12.84(S D=$ $2.83)$ and $11.33(S D=3.15)$. All remaining effects were not statistically significant. 


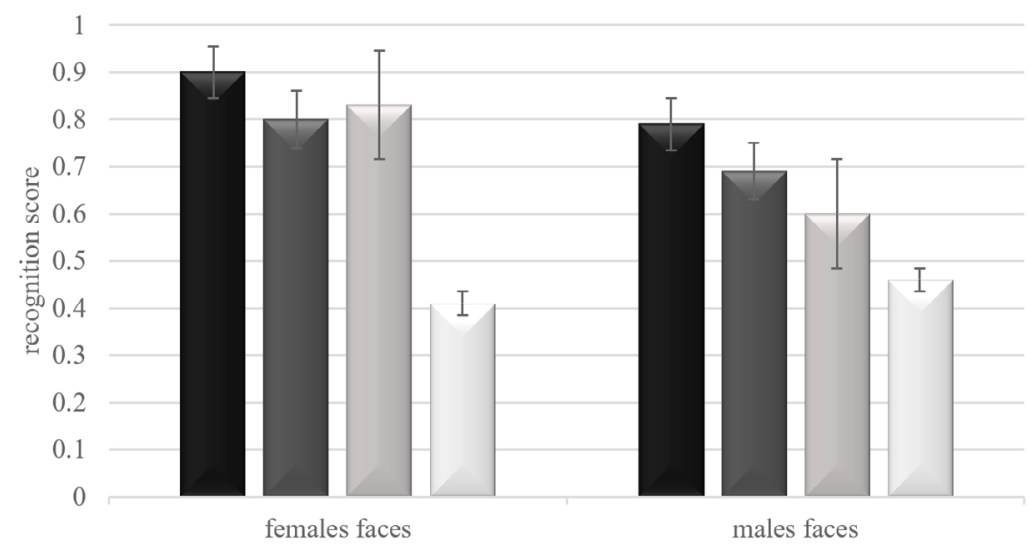

a single females $\mathbf{m}$ in-relationship females $\square$ single males $\square$ in-relationship males FIGURE 1.

Recognition of female and male faces according to the participants' gender and relationship status. Error bars represent intervals of $95 \%$ within-subjects confidence.

\section{DISCUSSION}

This study investigated the effect of gender and relationship status on face recognition. Our analyses showed higher face recognition in female than in male participants, regardless of their relationship status. A significant effect of relationship status on face recognition was observed only in males; specifically, single males demonstrated a higher face recognition than males in relationships, whereas similar face recognition was observed in single females and females in relationships. More specifically, single males demonstrated higher recognition for female than for male faces, whereas no differences were observed in single females and both females and males in relationships. In addition, higher episodic memory was observed in female than in male participants, whereas no significant effect of relationship status was observed on episodic memory. Together, relative to males in relationships, single males demonstrated higher face recognition, especially for female faces, but similar episodic memory, whereas females demonstrated similar face recognition and episodic memory regardless of their relationship status.

Our findings replicate prior studies with regard to (a) higher general face recognition and episodic memory in female participants and (b) the own-gender bias in female participants, that is, the fact that these participants demonstrated higher recognition for female than for male faces. The finding of a higher general face recognition in these participants mirrors studies demonstrating that females outperform males in tasks involving face recognition, independent of face age and ethnicity (Herlitz \& Lovén, 2013; Herlitz et al., 2013; McBain et al., 2009; Rehnman \& Herlitz, 2006, 2007). This finding also mirrors research demonstrating that females are better at recognizing and interpreting emotional facial expressions (McClure, 2000) as that infant girls spend more time looking at faces than boys (Connellan et al., 2000). The advantage females have in face processing has been attributed to a general greater interest in and knowledge of social aspects of the world (Kaplan, 1978; Kimura, 1999; Rehnman \& Herlitz, 2007).
As for the high verbal episodic memory in our female participants, studies suggest females tend to outperform males when the memory material is verbal (Astur, Ortiz, \& Sutherland, 1998; Lewin, Wolgers, \& Herlitz, 2001; Ruff, Light, \& Quayhagen, 1989; Ullman et al., 2008). This advantage is illustrated by a study in which females and males were tested on a series of tasks involving the recall and recognition of verbal material and abstract pictorial stimuli (Herlitz \& Yonker, 2002). Herlitz and Yonker (2002) found that females outperformed males on memory of verbal materials. The superiority of females in verbal processing has been also observed for autobiographical memory (Grysman, 2017; Grysman et al., 2016; Nahari \& Pazuelo, 2015). Since our episodic memory task implied processing verbal information, it is not surprising that female participants in our study have outperformed male participants. With regard to the own-gender bias in female participants, research suggests that females perform at a higher level on female than male faces (Cross et al., 1971; Lewin \& Herlitz, 2002; Wright \& Sladden, 2003). In contrast, males do not appear to show a corresponding own-gender bias for male faces. Several studies have found that males perform at a similar level for both male and female faces (Cross et al., 1971; Ino, Nakai, Azuma, Kimura, \& Fukuyama, 2010; Lewin \& Herlitz, 2002; Loven et al., 2011; Megreya et al., 2011; Wright \& Sladden, 2003), mirroring the performance of male participants in our study. The own-gender bias, as observed in females, has been interpreted as reflecting the fact that females' greater social interest is specifically directed towards other females (Loven et al., 2011). According to another social account, females may be more interested in female than in male faces due to the high value placed by society on female attractiveness (Cross et al., 1971; Ellis, Shepherd, \& Bruce,

\begin{tabular}{|c|c|c|}
\hline \multicolumn{3}{|c|}{$\begin{array}{l}\text { TABLE } 2 . \\
\text { Episodic Memory Scores of Participants According to Gender } \\
\text { and Relationship Status }\end{array}$} \\
\hline & Males & Females \\
\hline Single & $13.25(2.42)$ & $11.31(3.44)$ \\
\hline In a relationship & $12.6(3.08)$ & $11.35(3.02)$ \\
\hline
\end{tabular}


1973). Taken together, our findings replicate previous studies with regard to the higher general face recognition and episodic memory in female participants, as well as with regard to their own-gender bias.

Compared to other investigations of face recognition, the originality of our study lies in the assessment of relationship status. Our findings demonstrate higher face recognition in single females than in single males, as well as in females in relationships than males in relationships. Accordingly, regardless of their relationship status, females seem to outperform males on face recognition. The main finding of our paper was the high face recognition in single male participants, especially for female faces. Female participants, on the other hand, demonstrated similar face recognition regardless of their relationship status or the gender of faces. In our view, single males are specifically motivated by mating opportunity, and thus, tend to pay more attention to features of the opposite gender than single females do. On the other hand, individuals in relationships may benefit from affective and emotional comfort and stability, decreasing their motivation to process physical features of the opposite gender, which may explain why similar face recognition was observed in our female and male participants in relationships.

This suggestion is supported by studies demonstrating that while single individuals increase implicit attention to physically attractive opposite gender targets, individuals in relationships are inattentive to such stimuli (Maner et al., 2009; Maner et al., 2008). Our assumption is additionally supported by the individuation motivation account (Hugenberg, Wilson, See, \& Young, 2013), which states that individuals essentially process faces considered worthy of their attention. More specifically, enhanced motivation triggers selective attention (and deeper processing), which can facilitate face encoding. This model is supported by research demonstrating bias toward low processing of female faces when males consider a short-term mating strategy (Confer et al., 2010; Lu \& Chang, 2012; Wagstaff et al., 2015). Even though the individuation motivation account does not take into account the effect of relationship status, it does, however, provide support to the assumption that single males are motivated by mating opportunity, resulting in high memory for females faces.

The effect of motivation on face processing in single males can also be interpreted from an evolutionary perspective. According to one evolutionary account, humans possess fundamental social motives shaped by natural selection to produce behaviors that increase reproductive fitness (Kenrick, Neuberg, Griskevicius, Becker, \& Schaller, 2010). Interestingly, mate-related motives have been considered as one of fundamental social motives that exert important effects on social behaviors (Griskevicius, Cialdini, \& Kenrick, 2006; Karremans et al., 2011; Lydon et al., 1999; Maner et al., 2007; Maner et al., 2012; Ritter et al., 2010). Further, attention is the first step in information processing and in memory, and its evolutionary function is mainly related to information relevant to survival and reproductive goals (Dunbar \& Barrett, 2007), siven the limited attentional capacity and the diverse and complex social information that surrounds us. Hence, this attentional selectivity may result in high processing of female faces in single males. Single females, on the other hand, do not seem to demon- strate such an attentional bias, probably due to their enhanced overall memory for faces. That is, they process faces faster and more efficiently than males (Bowles et al., 2009; Godard \& Fiori, 2010, 2012; Megreya et al., 2011; Sommer et al., 2013), or they simply do not seek mating opportunities as much as males do.

One limitation of our study is the small sample size, which increases the risk of Type II statistical errors. Another is that we did not consider the duration of the relationship status of our participants. Future studies should take into account the duration of relationship as individuals in recently established relationships or those in open relationships may have high mating motivation, and thus, may demonstrate high face recognition. Another suggestion for future research is to explore face recognition according to sexual orientation, as single homosexual individuals may demonstrate higher face recognition for the same rather than for the opposite gender. Finally, it would be of interest to take response time into account, as this variable may provide better insight into participants' performance. This issue is important because accuracy measures may not reflect attentional processes by themselves. By addressing these limitations, future research may provide a comprehensive picture of the effect of relationship status on face recognition. Regardless of its potential limitations, this study shows, for the first time, that relationship status does impact face recognition and not episodic memory in general.

\section{REFERENCES}

Astur, R. S., Ortiz, M. L., \& Sutherland, R. J. (1998). A characterization of performance by men and women in a virtual Morris water task: a large and reliable sex difference. Behavioural Brain Research, 93, 185-190. doi: 10.1016/S0166-4328(98)00019-9 الس السلبل

Bowles, D. C., McKone, E., Dawel, A., Duchaine, B., Palermo, R., Schmalzl, L., ... Yovel, G. (2009). Diagnosing prosopagnosia: effects of ageing, sex, and participant-stimulus ethnic match on the Cambridge Face Memory Test and Cambridge Face Perception Test. Cognitive Neuropsychology, 26, 423-455. doi: 10.1080/02643290903343149 الس الس الس الس

Caplan, P. J., Crawford, M., Hyde, J. S., \& Richardson, J. T. E. (1997). Sex differences in human cognition. New York, NY: Oxford University Press.

Confer, J. C., Perilloux, C., \& Buss, D. M. (2010). More than just a pretty face: Men's priority shifts toward bodily attractiveness in short-term versus long-term mating contexts. Evolution and Human Behavior, 31, 348-353. doi: 10.1016/j.evolhumbehav.2010.04.002 سلس سلس

Connellan, J., Baron-Cohen, S., Wheelwright, S., Batki, A., \& Ahluwalia, J. (2000). Sex differences in human neonatal social perception. Infant Behavior and Development, 23, 113-118. doi:

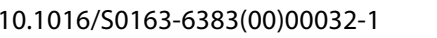

Conway, M. A. (2005). Memory and the self. Journal of Memory and Language, 53, 594-628. doi: 10.1016/j.jml.2005.08.005 السلالسالس

Cornoldi, C., \& Vecchi, T. (2004). Visuo-spatial working memory and individual differences. New York, NY: Psychology Press.

Cross, J. F., Cross, J., \& Daly, J. (1971). Sex, race, age, and beauty as 
factors in recognition of faces. Perception and Psychophysics, 10, 393-396. doi: 10.3758/bf03210319

Dunbar, R. I. M., \& Barrett, L. (2007). Oxford handbook of evolutionary psychology. Oxford, England: Oxford University Press.

Ebner, N. C., Riediger, M., \& Lindenberger, U. (2010). FACES--a database of facial expressions in young, middle-aged, and older women and men: development and validation. Behavior Research Methods, 42, 351-362. doi: 10.3758/BRM.42.1.351 سلسلسل|

El Haj, M., Antoine, P., \& Nandrino, J. L. (2016). More emotional facial expressions during episodic than during semantic autobiographical retrieval. Cognitive, Affective \& Behavioral Neuroscience, 16, 374-381. doi: 10.3758/s13415-015-0397-9 الس الس الس الس

El Haj, M., Fasotti, L., \& Allain, P. (2015). Destination memory for emotional information in older adults. Experimental Aging Research, 41, 204-219. doi: 10.1080/0361073X.2015.1001658 الس الس

El Haj, M., Raffard, S., Antoine, P., \& Gely-Nargeot, M. C. (2015). Emotion and destination memory in Alzheimer's disease.

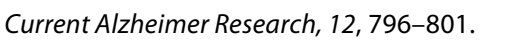

Ellis, H., Shepherd, J., \& Bruce, A. (1973). The effects of age and sex upon adolescents' recognition of faces. The Journal of Genetic Psychology, 123, 173-174. doi:

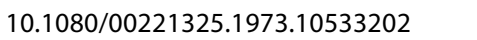

Godard, O., \& Fiori, N. (2010). Sex differences in face processing: Are women less lateralized and faster than men? Brain and Cognition, 73, 167-175. doi: 10.1016/j.bandc.2010.04.008 السلسلس

Godard, O., \& Fiori, N. (2012). Sex and hemispheric differences in facial invariants extraction. Laterality, 17, 202-216. doi: 10.1080/1357650X.2011.556641

Golby, A. J., Gabrieli, J. D., Chiao, J. Y., \& Eberhardt, J. L. (2001). Differential responses in the fusiform region to same-race and other-race faces. Nature Neuroscience, 4, 845-850. doi: 10.1038/90565 الس

Griskevicius, V., Cialdini, R. B., \& Kenrick, D. T. (2006). Peacocks, Picasso, and parental investment: The effects of romantic motives on creativity. Journal of Personality and Social Psychology,

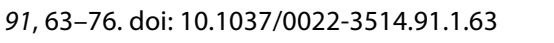

Grober, E., \& Buschke, H. (1987). Genuine memory deficits in dementia. Developmental Neuropsychology, 3, 13-36. doi: 10.1080/87565648709540361

Grysman, A. (2017). Gender differences in episodic encoding of autobiographical memory. Journal of Applied Research in Memory and Cognition, 6, 51-59. doi: 10.1016/j.jarmac.2016.07.012 سلس

Grysman, A., Merrill, N., \& Fivush, R. (2016). Emotion, gender, and gender typical identity in autobiographical memory. Memory,

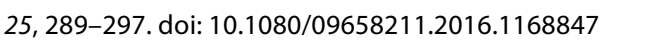

Halpern, D. F. (2000). Sex differences in cognitive abilities (3rd ed.). Mahwah, NJ: Lawrence Erlbaum Associates Inc.

Herlitz, A., \& Lovén, J. (2013). Sex differences and the own-gender bias in face recognition: A meta-analytic review. Visual Cognition, 21, 1306-1336. doi: 10.1080/13506285.2013.823140 الس الس الس

Herlitz, A., Reuterskiold, L., Loven, J., Thilers, P. P., \& Rehnman,
J. (2013). Cognitive sex differences are not magnified as a function of age, sex hormones, or puberty development during early adolescence. Developmental Neuropsychology, 38,

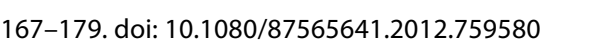

Herlitz, A., \& Yonker, J. E. (2002). Sex differences in episodic memory: The influence of intelligence. Journal of Clinical and Experimental Neuropsychology, 24, 107-114. doi: 10.1076/ jcen.24.1.107.970 سلبل.

Hugenberg, K., Wilson, J. P., See, P. E., \& Young, S. G. (2013). Towards a synthetic model of own group biases in face memory. Visual

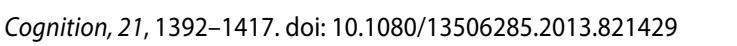
Ino, T., Nakai, R., Azuma, T., Kimura, T., \& Fukuyama, H. (2010). Gender differences in brain activation during encoding and recognition of male and female faces. Brain Imaging Behavior, 4, 55-67. doi: 10.1007/s11682-009-9085-0 媳

Kaplan, H. B. (1978). Sex differences in social interest. Journal of Individual Psychology, 34, 206-209. Wلس الس الس

Karremans, J. C., Dotsch, R., \& Corneille, O. (2011). Romantic relationship status biases memory of faces of attractive opposite-sex others: evidence from a reverse-correlation paradigm. Cognition, 121, 422-426. doi: 10.1016/j.cognition.2011.07.008

Kenrick, D. T., Neuberg, S. L., Griskevicius, V., Becker, D. V., \& Schaller, M. (2010). Goal-driven cognition and functional behavior: The fundamental-motives framework. Current Directions in Psychological Science, 19, 63-67. doi: 10.1177/0963721409359281 سلس سل

Kimura, D. (1999). Sex and cognition. Cambridge, MA: MIT Press. Lewin, C., \& Herlitz, A. (2002). Sex differences in face recognition-women's faces make the difference. Brain and Cognition, 50, 121-128. doi: 10.1016/S0278-2626(02)00016-7 البل1.

Lewin, C., Wolgers, G., \& Herlitz, A. (2001). Sex differences favoring women in verbal but not in visuospatial episodic memory. Neuropsychology, 15, 165-173. doi: 10.1037/08944105.15.2.165 سلب

Loven, J., Herlitz, A., \& Rehnman, J. (2011). Women's own-gender bias in face recognition memory. Experimental Psychology, 58, 333-340. doi: 10.1027/1618-3169/a000100 1.

Lu, H. J., \& Chang, L. (2012). Automatic attention towards face or body as a function of mating motivation. Evolutionary Psychology, 10, 120-135. doi: 10.1177/147470491201000113 سلس الس الس

Lydon, J. E., Meana, M., Sepinwall, D., Richards, N., \& Mayman, S. (1999). The commitment calibration hypothesis: When do people devalue attractive alternatives? Personality and Social Psychology Bulletin, 25, 152-161. doi: 10.1177/0146167299025002002 سلس

Maner, J. K., Gailliot, M. T., \& Miller, S. L. (2009). The implicit cognition of relationship maintenance: Inattention to attractive alternatives. Journal of Experimental Social Psychology, 45, 174-179. doi: 10.1016/j.jesp.2008.08.002 المالسلس

Maner, J. K., Gailliot, M. T., Rouby, D. A., \& Miller, S. L. (2007). Can't take my eyes off you: Attentional adhesion to mates and rivals. Journal of Personality and Social Psychology, 93, 389-401. doi: 


\subsection{7/0022-3514.93.3.389 سلس}

Maner, J. K., Miller, S. L., Moss, J. H., Leo, J. L., \& Plant, E. A. (2012). Motivated social categorization: fundamental motives enhance people's sensitivity to basic social categories. Journal of Personality and Social Psychology, 103, 70-83. doi: 10.1037/ a0028172 الس السلسلس

Maner, J. K., Rouby, D. A., \& Gonzaga, G. C. (2008). Automatic inattention to attractive alternatives: The evolved psychology of relationship maintenance. Evolution and Human Behavior, 29, 343-349. doi: 10.1016/j.evolhumbehav.2008.04.003 سلس سلس

McBain, R., Norton, D., \& Chen, Y. (2009). Females excel at basic face perception. Acta Psychologica, 130, 168-173. doi: 10.1016/j.actpsy.2008.12.005 الس السلسل

McClure, E. B. (2000). A meta-analytic review of sex differences in facial expression processing and their development in infants, children, and adolescents. Psychological Bulletin, 126, 424-453.

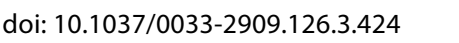

Megreya, A. M., Bindemann, M., \& Havard, C. (2011). Sex differences in unfamiliar face identification: Evidence from matching tasks. Acta Psychologica, 137, 83-89. doi: 10.1016/j. actpsy.2011.03.003 الس السلسلس

Nahari, G., \& Pazuelo, M. (2015). Telling a convincing story: Richness in detail as a function of gender and information. Journal of Applied Research in Memory and Cognition, 4, 363367. doi: 10.1016/j.jarmac.2015.08.005 سلسلس

Peirce, J. W. (2007). PsychoPy--Psychophysics software in Python. Journal of Neuroscience Methods, 162, 8-13. doi: 10.1016/j. jneumeth.2006.11.017 (لس

Rehnman, J., \& Herlitz, A. (2006). Higher face recognition ability in girls: Magnified by own-sex and own-ethnicity bias. Memory, 14, 289-296. doi: 10.1080/09658210500233581 السلسلسلاس

Rehnman, J., \& Herlitz, A. (2007). Women remember more faces than men do. Acta Psychologica, 124, 344-355. doi: 10.1016/j. actpsy.2006.04.004 السلسلس

Rhodes, M. G., \& Anastasi, J. S. (2012). The own-age bias in face recognition: a meta-analytic and theoretical review. Psychological Bulletin, 138, 146-174. doi: 10.1037/a0025750 الملسلس (2010)

Ritter, S. M., Karremans, J. C., \& van Schie, H. T. (2010). The role of self-regulation in derogating attractive alternatives. Journal of Experimental Social Psychology, 46, 631-637. doi: 10.1016/j. jesp.2010.02.010 المالسلس
Rubin, D. C., Schrauf, R. W., \& Greenberg, D. L. (2003). Belief and recollection of autobiographical memories. Memory and

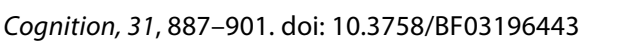

Ruff, R. M., Light, R. H., \& Quayhagen, M. (1989). Selective Reminding Tests: a normative study of verbal learning in adults. Journal of Clinical and Experimental Neuropsychology, 11, 539-550. doi: 10.1080/01688638908400912 البلالسلالس

Simpson, J. A., Gangestad, S. W., \& Lerma, M. (1990). Perception of physical attractiveness: Mechanisms involved in the maintenance of romantic relationships. Journal of Personality and Social Psychology, 59, 1192-1201. doi: 10.1037/00223514.59.6.1192

Snodgrass, J. G., \& Corwin, J. (1988). Pragmatics of measuring recognition memory: Applications to dementia and amnesia. Journal of Experimental Psychology: General, 117, 34-50. doi: 10.1037/0096-3445.117.1.34 سلس

Sommer, W., Hildebrandt, A., Kunina-Habenicht, O., Schacht, A., \& Wilhelm, O. (2013). Sex differences in face cognition. Acta Psychologica, 142, 62-73. doi: 10.1016/j.actpsy.2012.11.001 الر السلسل Ullman, M. T., Miranda, R. A., \& Travers, M. L. (2008). Sex differences in the neurocognition of language. In J. B. Becker, K. J. Berklry, N. Geary, E. Hampson, J. P. Herman \& E. A. Young (Eds.), Sex differences in the brain from genes to behavior (pp. 291-309). Oxford, England: Oxford University Press.

Voyer, D., Voyer, S., \& Bryden, M. P. (1995). Magnitude of sex differences in spatial abilities: a meta-analysis and consideration of critical variables. Psychological Bulletin, 117, 250-270. doi: 10.1037/0033-2909.117.2.250 سلس (1)

Wagstaff, D. L., Sulikowski, D., \& Burke, D. (2015). Sex-differences in preference for looking at the face or body in short-term and long-term mating contexts. Evolution, Mind and Behaviour, 13, 1-17. doi: $10.1556 / 2050.2015 .0003$ سلس

Wright, D. B., \& Sladden, B. (2003). An own gender bias and the importance of hair in face recognition. Acta Psychologica, 114, 101-114. doi: 10.1016/S0001-6918(03)00052-0 السلسلس

RECEIVED 04.03.2019| ACCEPTED 23.10.2019 